\title{
Implicancias del Brexit en la Unión Europea
}

\author{
Josefina del Prado*
}

\section{RESUMEN}

El 23 de junio de 2016 será una fecha difícil de olvidar, principalmente en Europa. ¿Debe el Reino Unido seguir siendo parte o no de la Unión Europea (UE)? fue la pregunta planteada en el histórico referéndum en el que la mayoría, por un pequeño margen, votó a favor de abandonar la UE.

Es así como el Reino Unido se convirtió en el primer país que decidió salir de la Unión Europea, donde permaneció más de cuatro décadas, imprimiéndole con esta decisión un golpe sin precedentes a un proceso de integración emblemático a nivel mundial.

En lo que parece un proceso irreversible, el Reino Unido comenzó el 29 de marzo de 2017 el proceso formal para abandonar la Unión Europea (UE), activando el artículo 50 del Tratado de Lisboa que prevé un mecanismo para la retirada voluntaria y unilateral de un país de la Unión Europea.

El resultado del referéndum y la mención expresa de la recuperación de la independencia y de la soberanía por parte de la primera ministra británica Theresa May reflejan la primacía de las posiciones euroescépticas o eurofóbicas en la isla frente a las europeístas.

En las líneas que siguen, reflexionaremos respecto a las fuerzas subyacentes al proceso de integración europeo, sus principales hitos, para pasar a analizar el papel del Reino Unido en el mismo y el impacto del retiro de este de la UE.

Palabras clave: integración, globalización, interdependencia, nacionalismo, populismo, euroescepticismo, eurofobia

* Profesora de la Pontificia Universidad Católica del Perú de Relaciones Internacionales, Lima, Perú. Máster en Relaciones Internacionales otorgado por la Universidad de Warwick, Inglaterra. Correo electrónico: finadelprado@ yahoo.com 


\section{Consequences of Brexit for the European Union}

\section{Abstract}

June 23, 2016, will be a day difficult to forget, mainly in Europe. Should the United Kingdom remain part of the European Union (EU) or not?, was the question posed in the historic referendum and the majority, with a very little margin, voted in favor of leaving the EU.

This is how the United Kingdom became the first country that decided to leave the European Union, where it remained for more than four decades, dealing an unprecedented blow to an emblematic integration process worldwide. In what it seems an irreversible process, the United Kingdom began on March 29, 2017, the formal process to leave the European Union (EU), activating Article 50 of the Treaty of Lisbon that provides a mechanism for the voluntary and unilateral withdrawal of a country of the European Union.

The result of the referendum and the express mention of the recovery of independence and sovereignty by the British Prime Minister Theresa May reflect the primacy of Eurosceptic or Europhobic positions on the island against the pro-Europeans. In the following lines, we will reflect on the underlying forces of the European integration process, its main milestones, to analyze the role of the United Kingdom in it and the impact of the withdrawal of the UR to the EU.

Keywords: integration, globalization, interdependence, nationalism, populism, euroescepticism, europhobia

\section{Entre el universalismo y la fragmentación}

La decisión adoptada por el Reino Unido no surge de un momento a otro. No es la primera vez que se evidencia las distancias entre Londres y la UE. Desde su creación hasta el momento, las tendencias integradoras de la Europa unida habían triunfado frente a las fuerzas detractoras que de tanto en tanto se han pronunciado a lo largo de este proceso.

A través de la historia, el universalismo y la fragmentación son dos tendencias que han contribuido a determinar la dinámica de las relaciones internacionales. Siempre hay quienes apuestan a los beneficios de una mayor cooperación, de la interdependencia y de ser posible la integración como garantía de paz y prosperidad y quienes se apegan a referentes territoriales, ideológicos, cuyas posiciones más extremas pueden llevar a la fragmentación. Recordemos los tiempos medioevales en los que la Iglesia buscaba un poder centralizado, mientras que los señores feudales atomizaban el poder. Hoy podemos hablar de la fuerza de la globalización y sus detractores, del multilateralismo versus el unilateralismo, del federalismo europeo frente a la eurofobia. 
Durante las últimas décadas del siglo XX, el fenómeno de globalización impulsó fuerzas aglutinantes, los regionalismos se relanzaron en su fórmula abierta y se hablaba de un mundo de bloques regionales.

En la década de 1990, como reflejo de la predominancia de estas fuerzas, se crea el Mercado Común del Sur (Mercosur), se suscriben el Tratado de Libre Comercio de América del Norte (TLCAN, o NAFTA en inglés), se constituye APEC y se refuerzan el proceso europeo con el Tratado de Maastricht y el andino con la creación de la Comunidad Andina (CAN), en reemplazo del Pacto Andino. Sin embargo, se manifiestan, paralelamente, tendencias atomizadoras en casos como la fragmentación de la Yugoslavia y de la Unión Soviética.

En 1992, el entonces secretario general de las Naciones Unidas, Butros Gali señalaba: "Hemos entrado en una era de transición mundial marcada por tendencias singularmente contradictorias. Asociaciones regionales y continentales de los Estados están elaborando mecanismos para profundizar en la cooperación y suavizar algunas características contenciosas de las rivalidades de soberanía y nacionalismo" (1992, p. 5). Gali destacaba el contexto de debilitamiento de las fronteras nacionales y las decisiones de los Estados de ceder algunas prerrogativas de soberanía a asociaciones políticas de mayor alcance.

La regionalización juega hoy en día un papel fundamental en la configuración del orden mundial. Como señala Charles Oman,

[...] los convenios regionales son positivos en la medida en que "generen el comercio", es decir, en tanto refuercen la globalización reduciendo los impedimentos de la política económica al comercio entre países y estimulando la competencia al interior de la economía de una región. (1996, p. 21).

Otros temen que estos procesos puedan derivar en un «regionalismo degenerado» es decir «en una intensificación de la regionalización que conduzca a una fragmentación del sistema mundial de comercio, hasta constituirse en un cierto número de bloques regionales relativamente cerrados y hostiles» (Oman, 1996, p. 21). Cabe destacar que más del $90 \%$ de los miembros de la OMC participan en bloques comerciales multiplicados sobre todo desde fines del siglo XX.

Coincidimos con Oman cuando afirma que, «en la práctica, la globalización y la regionalización tienden a reforzarse mutuamente, sobre todo, en tanto la regionalización estimula la competencia en los mercados regionales» (1996, p. 73).

Consideramos que estas fuerzas, universalismo y fragmentación, siguen siendo determinantes, lo que se demuestra en hechos como el Brexit. Las fuerzas globalizadoras de la posguerra Fría contribuyeron en su momento a lograr la a ansiada Unión Política con el Acuerdo de Maastricht y las tendencias populistas nacionalistas llevaron al Brexit. 


\section{Surgimiento de la UE}

La UE es un proceso regional de integración nacido a mediados del siglo XX que sido interpretado a través de distintos enfoques de las relaciones internacionales.

Desde el realismo, la crisis de la unión ha sido explicada como resultado de la desaparición de la amenaza soviética y la consecuente reaparición de los factores de fragmentación. Por su parte los transnacionalistas ven el proceso de la construcción europeo como derivada de la condiciones de interdependencia (Barbé, 1995, pp. 276 y 277). La integración europea parte de un acercamiento fundamentalmente económico bajo el supuesto liberal de que el libre comercio es la clave para la armonía global y que la proliferación de democracias garantizarían la paz.

En este sentido la UE es entendida como una iniciativa europeísta que se lanza con el fin de evitar más conflictos entre sus miembros, afrontar los retos económicos y financieros y mantener el protagonismo en un mundo que dejó de ser eurocéntrico.

Se trataba de construir una nueva Europa unida, ante el surgimiento de un mundo bipolar donde las protagonistas eran dos superpotencias y ya no potencias europeas que había regido el orden internacional hasta ese momento y evitar que este nuevo orden mundial la dividiera más.

Respecto a las vías para lograrla, por un lado, estaban los federalistas, que buscan una unidad política y se apoyan en valores compartidos y una identidad común, y por otro, los funcionalistas, que parten de uniones parciales que crearan solidaridades de hecho en el ámbito económico para luego pasar a lo estrictamente político. Es decir, para los federalistas los Estado-nación deben ser reemplazados y para los funcionalistas, complementados por unidades políticas supranacionales (Moreno, 2001, p. 358). En la implementación de la integración europea el federalismo ha suscitado sensibilidades en términos de cesión de soberanía por lo que ha primado el enfoque funcionalista.

Para revisar los factores que llevan al inicio de este proceso hay que remitirse al Plan Schumann y el Tratado de París que da nacimiento a la Comunidad Europea del Carbón y el Acero (CECA) y sus antecedentes como movimientos europeístas tales como el Movimiento Federalista Europeo (1943) o el Movimiento Europa Unida promovido en 1947 por Winston Churchill (Calduch, 1991, p. 178). Recordar el papel de la resistencia antifascista representado principalmente por corrientes de opinión como el Movimiento Socialista para los Estados Unidos de Europa, los Nuevos Equipos Internacionales democristianos, la participación de la opinión pública a través de organizaciones privadas partidarias de la unión, cuya creciente multiplicación contribuye al impulso de las fórmulas comunitarias. En 1947 se constituye un 
Comité Internacional de Coordinación para la Unión Europea integrado por los más influyentes grupos, dando lugar al Movimiento Europeo Internacional. Este marco contribuirá a lanzar el proceso de negociaciones entre los gobiernos europeos cuyo primer hito fue la creación del Consejo de Europa el 5 de mayo de 1949 (Moreno, 2001, p. 358).

Debemos también destacar como fuerzas coadyuvantes al nacimiento del proceso de integración europeo el contexto de la Guerra Fría, el papel de Estados Unidos que lo respaldaba en la medida en lo veía como favorable a la recuperación económica de Europa Occidental y a la contención del comunismo soviético.

\section{Hitos de la integración (Moreno, 2001, pp. 357-376)}

La Unión Europea ha sido percibida como una integración exitosa, referente de muchas otras, que fue cumpliendo una a una las etapas planteadas - el paso del mercado común al de Comunidad Económica Europea y la Unión Europea-para cumplir con sus fines y objetivos.

Los objetivos de la Unión Europea establecidos formalmente en sus instrumentos de creación son: promover la paz, sus valores y el bienestar de sus ciudadanos; ofrecer libertad, seguridad y justicia sin fronteras interiores; favorecer un desarrollo sostenible basado en un crecimiento económico equilibrado y en la estabilidad de los precios, una economía de mercado altamente competitiva con pleno empleo y progreso social, y la protección del medio ambiente; combatir la exclusión social y la discriminación; promover el progreso científico y tecnológico; reforzar la cohesión económica, social y territorial y la solidaridad entre los Estados miembros; respetar la riqueza de su diversidad cultural y lingüística; establecer una unión económica y monetaria con el euro como moneda (Unión Europea, 2018).

En un breve repaso de las etapas vividas por la UE encontramos como los principales tratados que han marcado su historia: Comunidad Europea del Carbón y del Acero - CECA (1951), Tratados de Roma (1957), Acta de Unión Europea (1987), Maastricht (1993), Ámsterdam (1997), Niza (2001) y Lisboa (2007).

El 9 de mayo de 1950, el ministro de Exteriores de Francia, Robert Schumann planteó a Alemania la oferta de producir conjuntamente carbón y acero, iniciativa que tenía como antecedente la propuesta del canciller Konrad Adenauer ańos antes de crear un pool de industrias siderúrgicas. Schuman señaló que la reconciliación entre Francia y Alemania significaría: «los primeros pasos concretos de una federación europea, indispensable para asegurar la paz». La iniciativa no se limitada a ambos países, Benelux (Bélgica, Holanda y Luxemburgo) e Italia se sumaron, pero 
Gran Bretańa no quiso participar (Moreno, 2001, p. 360). Así, el 18 de abril de 1951 se firmó el Tratado Constitutivo de la Comunidad Europea del Carbón y del Acero (CECA), el cual entró en vigor el 25 de julio de 1952.

El siguiente paso propuesto fue la creación de la Comunidad Europea de Defensa pero, en este caso, a diferencia del anterior, no se contó con el respaldo de la opinión pública europea, ni de la clase política francesa y principalmente de EE.UU., que temían el fortalecimiento militar de Alemania.

Siguiendo con el avance de este proceso, el 25 de marzo de 1957 se firmaron los Tratados de Roma que crearon la Comunidad Económica Europea (CEE) y la Comunidad Europea de la Energía Atómica (Euratom), instaladas en Bruselas con miras a constituir un mercado común. Los firmantes fueron «los Seis»: Francia, Benelux, Alemania e Italia. Entre 1969 y 1980 se dio la ampliación comunitaria e ingresan primero Gran Bretaña, Irlanda y Dinamarca en $1972^{1}$.

Por su parte, el Acta Única Europea que entró en vigor el 1 de enero de 1987 y modificó los Tratados constitutivos e incluyó procedimientos de la cooperación política de los ya en ese entonces, doce miembros a fin de crear un espacio de libre circulación de mercancías, servicios, capitales y personas.

En el marco de la tercera ola democratizadora, iniciada con hechos como la caída de dictaduras europeas como en Portugal o España en la primera mitad de la década de 1970, se da en el proceso de integración europeo ya llamada «ampliación hacia el Sur» con el ingreso de Grecia en 1981 y de España y Portugal en 1986.

Al final de la Guerra Fría, se logró el Acuerdo de Maastricht en medio de una importante crisis económica y política. Este Tratado introdujo una nueva estructura institucional: la Comunidad Económica Europea, la Política Exterior y de Seguridad Común (PESC) y la Cooperación en Asuntos de Justicia e Interior.

Cabe destacar también en este breve repaso de hitos de integración la creación de la zona Schengen (Luxemburgo) en 1985, cuando Alemania, Francia y los países del Benelux suprimieron los controles fronterizos internos. Luego se sumaron otros países siendo hoy 26 los que la integran de los cuales 22 son miembros de la UE.

Otro momento destacable es el establecimiento del Euro en 2002. La Eurozona se inició con doce países de la UE que introdujeron el euro como moneda de curso legal; es menester recordar que como unidad de cuenta ya existía desde 1999. La sede

\footnotetext{
En Noruega ganó el «No» en la consulta directa hecha a su población; sin embargo, pertenece al Espacio Económico Europeo (EEE) y es parte del Acuerdo Schengen.
} 
del Banco Central Europeo (BCE) está en Fráncfort y actualmente integran la zona euro 18 Estados miembros de la UE.

El aumento de miembros de la UE en 2004, con el ingreso de Chipre, Eslovaquia, Eslovenia, Estonia, Hungría, Malta, Letonia, Lituania, Polonia y la República Checa, en 2007 de Bulgaria y Rumania y en 2013 Croacia, es un hecho que en el contexto de crisis migratoria y su relación con el Brexit cobra mayor relevancia.

Recordemos asimismo la propuesta de una nueva constitución para la UE, que fue rechazada por los votantes franceses y holandeses en el referéndum de 2005. La Constitución finalmente es reemplazada por el Tratado de Lisboa en 2009 cuyo objetivo general ha sido descrito como un intento de modernizar la UE, reforzando el papel de los ciudadanos, mediante la racionalización de una organización más democrática. Ha sido criticado por los detractores de la fórmula federalista.

A lo largo de este proceso, el Reino Unido ha mostrado sus distancias respecto a las posiciones europeístas: optó por no adoptar el euro y quedarse fuera de la zona Schengen y ha tratado constantemente de obtener más flexibilidad respecto a sus propios asuntos a fin de salvaguardar sus intereses bajo un enfoque más independiente que el de sus socios comunitarios.

El tema de la soberanía y su posible cesión en nombre la unidad europea reflejado en el referéndum británico ha estado presente desde un inicio en las discusiones para la integración. Los Estados de la Europa Occidental no estaban dispuestos a renunciar a sus soberanías por lo que fue necesario buscar un compromiso que no llegara a constituir un Estado federal pero que ofreciera algo más que solo cooperación entre los Estados (Moreno, 2001, p. 358). El logro de este difícil equilibrio entre las competencias delegadas y la conservación de la soberanía será telón de fondo permanente en la dinámica del proceso de integración europeo.

\section{Participación británica en la UE}

Como ya ha sido mencionado, la insatisfacción o escepticismo británico no ha sido novedad. El Reino Unido fue siempre asociado a una posición crítica en distintas fases y aspectos del proceso europeo.

Durante las distintas etapas de la integración europea, el Reino Unido cuestionó desde dentro, decisiones e iniciativas propuestas por sus socios y no se sumó a compromisos que se fueron dando, como la creación del espacio Schengen y la zona euro.

Así, el Reino Unido fue invitado desde un principio a ser parte del mercado común europeo, participó en las conversaciones iniciales, pero optó por privilegiar la 
Commonwealth o la creación de la Asociación Europea de Libre Cambio (EFTA) en la que participan Suecia, Noruega, Dinamarca, Suiza, Austria y Portugal.

Como destaca María del Dolores Béjar, en un principio, el Reino Unido se mantuvo al margen de la unidad con el continente porque «le restaba libertad de acción internacional y subordinaba su política económica a organismos supranacionales» (2011, p. 232). Sin embargo, cuando la Comunidad empezó a evidenciar sus beneficios, el Gobierno británico solicitó su ingreso y De Gaulle vetó dos veces su incorporación (en 1963 y 1967). Es recién en 1969, año en que dimite el general De Gaulle, cuando se reanudan las conversaciones, y en 1973 entra a la CEE, junto con Irlanda y Dinamarca.

Si bien el Reino Unido logró ingresar a la CEE, las dudas y suspicacias respecto a la participación británica, alimentadas por su condición insular y su cercanía con los Estados Unidos, subsistieron en la relación con la Unión.

Pese a su ingreso en 1973, dos años después, decidió realizar un referéndum para confirmar su afiliación a la CEE, igual que en 2016. Fue el primero que se realizó sobre este tema en todo el Reino Unido; antes se habían realizado en Escocia, Gales e Irlanda del Norte, así como en Londres y otras ciudades.

Los años siguientes se caracterizaron por el constante enfrentamiento entre el Reino Unido, Francia y Alemania, aunque en los ochenta las relaciones se calmaron un poco, cuando se firmó el Tratado de Maastricht y el Reino Unido decidió quedarse fuera del Euro.

En 2013, la presión del sector euroescéptico cobró mayor fuerza y finalmente, a diferencia de 1975, la no permanencia en la Unión se impuso en el referéndum de 2016, con lo que se marcó un nuevo hito en lo historia de este largo proceso.

\section{El Brexit}

El Brexit marca un hecho sin precedentes. Como antecedente solo existía el caso de Groenlandia, que abandonó la CEE en 1985. Algunos mencionan también el caso de Argelia que, al lograr su independencia, logró una salida no negociada. Sin embargo, consideramos que ambos casos difieren sustantivamente del caso que nos ocupa, tanto por el fondo como la forma ya que hasta el Tratado de Lisboa (artículo 50) de 2007, los tratados comunitarios no habían previsto disposiciones sobre la posibilidad de que un Estado miembro se saliera de la UE.

Luego de los resultados del referéndum, hubo voces que llamaron a revisar esta decisión, repetir la consulta o ignorarla. Sin embargo, la primera ministra británica 
Theresa May ha dicho que no se convocara a otro referéndum y que se aspira una «futura asociación sólida y especial» con la Unión.

Los pilares de la campaña del Brexit estuvieron centrados en la recuperación de fronteras nacionales, cortar el flujo de inmigrantes y desligarse del control de Bruselas.

Respecto a las raíces del Brexit, se destacan como los factores más saltantes la creación de la unión monetaria con el Tratado de Maastricht de 1992 — acusada de no contar con los mecanismos suficientes para compartir los riesgos de la crisis-y la ampliación de la UE en 2004 (Hall, 28 de junio de 2016). Habría que enmarcar estos factores, dentro de otros más amplios como la fuerza de los movimientos euroescépticos y antiglobalizadores.

Si bien el Reino Unido se mantuvo fuera del euro y no se incorporó a la zona Schengen, desde el referéndum de 1975, no manejaba una retórica que llamara a la ruptura total y más bien pugnaba por un papel protagónico en su seno.

Las posiciones euroescépticas se agudizaron con la llegada de David Cameron a Downing Street, quien en su campaña prometió un referéndum para decidir sobre la delegación de soberanía a la UE. El Partido de la Independencia del Reino Unido (United Kingdom Independence Party o UKIP), por su parte, también tiene un papel importante en este contexto liderando la posición eurofoba.

La tensión entre la UE y el Reino Unido se agudizó en medio de la crisis del euro y el aumento de la inmigración de países del este. Si bien, el Reino Unido cuenta con una cláusula de exención conocida como opt-out —al igual que Dinamarca一, el impacto de la crisis del euro alimenta los sentimientos críticos a la Unión en la isla.

El 1 de enero de 1999 el euro pasó a ser la moneda oficial y los billetes y monedas empezaron a circular en 2002. La zona euro se inició con doce miembros y hoy cuenta con diecisiete ${ }^{2}$.

La crisis financiera global impactó a la UE, particularmente a la zona euro donde se evidenciaron debilidades para reaccionar frente a esta crisis especialmente en términos de mecanismos de supervisión y control financiero, lo cual generó un clima de creciente desconfianza frente a las ventajas de la unión monetaria.

Recuerda Joseph Stiglitz (2012, p. 14) que se pensó que el euro integraría más a los países, sin embargo, en la práctica, su efecto ha sido justamente el contrario al abrir viejas heridas y despertar nuevos antagonismos.

\footnotetext{
2 Los dieciséis miembros son: Alemania, Austria, Chipre, Eslovaquia, Eslovenia, España, Estonia, Finlandia, Francia, Grecia, Irlanda, Italia, Luxemburgo, Malta, Países Bajos y Portugal.
} 
Así, por ejemplo, Francia impulsó la unión monetaria como una forma de reducir el peso del Bundesbank de Alemania en los asuntos económicos europeos. Sin embargo, la crisis del euro lejos de debilitar su posición confirmó su poder en la Unión.

Las críticas sobre la zona euro se agudizaron en este marco, como la del nobel Stiglitz quien señala: «la historia de la eurozona es una alegoría moral: demuestra que los lideres que no están en contacto con sus electores son capaces de concebir sistemas que no convienen a sus ciudadanos. Enseña asimismo que, con frecuencia, los intereses financieros han predominado en el desarrollo de la integración económica y que la ideología y los intereses descontrolados pueden generar unas estructuras económicas tal vez beneficiosas para unos pocos, pero peligrosas para grandes sectores de la ciudadanía» (Stiglitz, 2016, p. 13).

La ampliación de la membrecía a países del este europeo en 2004 es también un factor asociado al Brexit en la medida en que uno de los temas bandera de sus impulsores era controlar la inmigración en la Isla.

Curiosamente en ese entonces, la preocupación no venía del Reino Unido, quien en ese tiempo apoyó la ampliación en la medida en que contribuía a aumentar su mano de obra y a su crecimiento económico.

Sin embargo, diez años después el fenómeno migratorio y sus efectos son temas bandera de los representantes del Brexit. Las cifras de inmigrantes fueron aumentando en el Reino Unido ${ }^{3}$ lo que aumentó la presión sobre un sector de la población que se sintió amenazado, principalmente en términos laborales y respecto al acceso a servicios como los de salud. Esta percepción fue creciendo y alimentando las posiciones euroescépticas en el Reino Unido. Este sentimiento alcanza también a varios países de la Unión, sobre todo a sectores que cuestionan los beneficios de la globalización en la medida en que su situación no ha mejorado o ha empeorado principalmente en términos laborales y económicos.

Sin embargo, la percepción en el Reino Unido no sería exacta. Como señala Peter Hall (28 de junio de 2016):

[...] la mayoría de los estudios muestran que la inmigración ha sido beneficiosa para el Reino Unido, que de lo contrario tendría una población cada vez menor. Genera demanda económica y trabajos que de otro modo no existirían. En las regiones del Reino Unido, los aumentos en la inmigración no parecen haber reducido las oportunidades de empleo o el salario de los trabajadores nacidos en Gran Bretańa.

\footnotetext{
3 Se estima en 123000 personas la inmigración hacia el Reino Unido procedentes de la EU en 2013, la cual se incrementó a 178000 en 2014.
} 
Coincidimos también en que, "las percepciones son todo en política y, alimentadas por historias histéricas en la prensa sensacionalista, la mayoría de la gente piensa que el Reino Unido tiene tres veces más inmigrantes que la UE». (Hall, 28 de junio de 2016).

La inmigración es estimulada no solo por la ampliación de miembros en la UE sino por factores como la grave situación en Siria y la crisis económica global que generaron un clima de mayor incertidumbre, caldo de cultivo para que los partidos y movimientos nacionalistas populistas ganen terreno en Europa. Es así que, si bien el Brexit fue la única salida de la Unión que se ha plasmado en un referéndum y que está en marcha, esta decisión intensifico voces llamando al Frexit (Francia): Nexit (Holanda), Grexit (Grecia), Itexit (Italia), Gext (Alemania), Fexit (Finlandia), Dexit (Dinamarca), Auxt (Austria).

\section{Brexit y antiglobalización}

Como hemos señalado, el proceso de integración europeo nació para enfrentar crisis, para paliar efectos de una guerra mundial que tuvo como importantes protagonistas a nacionalismos radicales. Hoy el escenario parece repetirse, pero esta vez la reacción alimenta tendencias contrarias a la Unión Europea. Los populismos nacionalistas han encontrado terreno fértil en escenarios de crisis económica, financiera, desempleo, inequidad o desigualdad.

Hay quienes señalan que los sectores más afectados por la globalización han sido las clases medias y bajas de Europa y de Estados Unidos. Esta situación habría contribuido al aumento de influencia de los movimientos nacionalistas, populistas que recogen las insatisfacciones de los ciudadanos principalmente en términos socioeconómicos.

En la década de 1990 cuando la Unión Europea llegaba a su máximo esplendor y se constituía en una unión política, el entusiasmo frente a la globalización y sus bondades estaba en su pico a nivel mundial. En dichos años, el impulso a procesos integracionistas se evidenciaba en el fortalecimiento de los bloques existentes o el surgimiento de nuevos. Eran tiempos donde la globalización era vista mayoritariamente como una tendencia natural, irreversible, que no admitía vuelta atrás.

La globalización «es política, tecnológica y cultural, además de económica» como afirma Anthony Giddens (2000, pp. 19-25), quien precisa que se trata de «una serie compleja de procesos, y no es uno solo. Joseph Stiglitz (2002, p. 34) centra la definición más a su dimensión económica y señala que se trata de, «la integración más estrecha de los países y los pueblos del mundo, producida por la enorme reducción de los costes de transporte y comunicación, y el desmantelamiento de las barreras artificiales a los flujos de bienes, servicios, capitales, conocimiento y (en menor grado) personas a través de las fronteras». 
Pero un aspecto que cabe resaltar como fenómeno asociado al Brexit es que, la globalización es también «la razón del resurgimiento de identidades culturales locales en diferentes partes del mundo. [...] Los nacionalismos locales brotan como respuesta a tendencias globalizadoras, a medida que el peso de los Estados nación más antiguos disminuye» como Giddens explica (2000, pp. 25-26).

$\mathrm{Y}$ es que las consecuencias de la globalización no son parejas, incluso dentro de un mismo Estado, existen norte y sur en un mismo país, así encontramos a los globalizados y a los que no, los interconectados y los que no lo están tanto o nada. En este sentido es frecuente oír que fenómeno trae ganadores y perdedores.

En este marco, surgen lo movimientos antiglobalización o antimundialización, como reacción o preocupación fundamentalmente frente a su eventual impacto económico-comercial. Algunos reconocen como hito inicial de esta tendencia a los movimientos zapatistas en Chiapas coincidentes con la entrada en vigor del Tratado de Libre Comercio de Norteamérica (TLCAN o NAFTA en inglés) y otros como las protestas con el Acuerdo Multilateral de Inversiones (AMI). A nivel europeo, las reacciones contra el Acuerdo de Maastricht marcaron un punto de inflexión. Las crisis financieras de esta década nutrieron también a esta tendencia. La iniciativa ATTAC, que promueve el control de los mercados financieros, nace en este contexto. Las protestas en Seattle en el marco de la reunión de la Organización Mundial de Comercio en dicha ciudad, al inicio del siglo XXI, evidenciaron sin duda un punto de quiebre histórico en relación a los movimientos mundiales antiglobalizadores (Seoane y Taddei, 2001, pp. 105-129).

Consideramos que el resultado del referéndum en el Reino Unido en junio de 2016 es reflejo también de esta tendencia dado que las voces detractoras a los efectos de la globalización alimentaron a sus seguidores. Y el fenómeno no es exclusivo del Reino Unido. El peligro está latente y Europa enfrenta el reto de no permitir que las fuerzas antiglobalizadoras sigan avanzando y generando un efecto contagio no deseado.

El Brexit ha vuelto a poner sobre el tapete el debate entre nación o Europa, entre fraccionamiento y universalismo. La eventual pérdida o disminución de soberanía de los Estados nación es para los más entusiastas frente a la globalización una consecuencia natural y no necesariamente negativa. La mayor interdependencia llevará a una mayor cooperación para solucionar problemas y enfrentar retos. La supranacionalidad es un grado muy alto de cooperación donde los Estados ceden voluntariamente soberanía por un bien mayor, para crear entidades capaces de abordar temas de una manera más efectiva y eficiente. Sin embargo, este enfoque no es compartido por los más escépticos o pesimistas frente a la globalización, sus posibilidades y efectos. 
Uno de los argumentos más fuertes del Brexit fue el alegar que el Reino Unido había perdido soberanía frente a Bruselas. Este sentimiento se exacerba cuando las instancias o mecanismos supranacionales creados fallan o no responden de manera adecuada a las demandas y problemas de los ciudadanos, más aún en medio de la crisis del global y debilidad de la zona euro para afrontarla.

En estas circunstancias, los referentes nacionales se fortalecen y recuperar el control se convierte en un deber. La mira se pone en los líderes comunitarios y burocracia de Bruselas a quienes se les ve distantes a un electorado apegado más a sus referentes nacionales que a los europeos en su conjunto.

\section{Las implicancias del Brexit para Europa}

El papel de los órdenes regionales hoy en día es fundamental, los cambios en la correlación de fuerzas dentro de las mismas son los que van dando lugar a nuevos órdenes que determinan la dinámica de las relaciones internacionales.

Así, es claro el papel relevante que el proyecto europeo ha tenido en la política internacional contemporánea. La UE constituye un actor internacional que no puede compararse a otros por su estructura y conformación. Congrega a potencias históricas que se han ido adaptando a los tiempos a través de sucesivos tratados, en un proceso de marchas y contramarchas, que, en la medida en que integra a más miembros, evidencia más de una tendencia y velocidad.

El impacto de la salida del Reino Unido — la segunda economía europea, luego de Alemania y la primera potencia militar de la Unión — sin duda significa un gran cambio en el equilibrio de fuerzas de la Unión y en sus relaciones con otros actores relevantes. La sola decisión del Reino Unido ya demandaba cambios y reformas, ajustes necesarios para una mejor adaptación a los retos actuales.

El Brexit afectará también la alianza entre Londres y Washington con EE.UU. y entre la de la Union Europea con la potencia estadounidense. Hasta antes de esta decisión la relación especial con EE.UU. era factor que le daba un valor específico al Reino Unido dentro de la Unión, además de su condición de miembro del Consejo de Seguridad y de potencia nuclear.

En el plano internacional, un efecto directo del Brexit se da en relación a lo que se ha llamado la relación trasatlántica, es decir, los lazos entre la UE y EE.UU., cuyo interlocutor más cercano y directo es el Reino Unido. La relación con EE.UU. se ha visto también alterada con la llegada de Donald Trump y su política exterior. El Brexit añade un elemento adicional que hace que la relación UE-EE.UU., merezca ajustes y se adapte a esta nueva dinámica. 
El retiro del Reino Unido llama a un reacomodo de fuerzas. Así, Alemania tendrá menos contrapesos y se afianzará como el líder de la UE. Esta situación implicará ajustes tanto en las relaciones intraeuropeas como fuera de la Unión.

El papel de Francia también sufrirá cambios. Si bien ha jugado un papel determinante también en estas casi siete décadas, entendemos que el Brexit le demandará mayores responsabilidades. Se dejará extrañar la relación París-Londres en el seno de la UE pues si bien ambos difieren respecto a la dirección del proyecto europeo, ambos han coincido en aspectos como el papel preponderante que debe tener el Consejo Europeo en cualquier proceso de toma de decisiones, por encima de la Comisión y su trabajo se ha plasmado en situaciones como en la intervención conjunta en Libia en 2011 (Morillas, 2016).

Si bien Alemania y Francia no detentan el mismo poder ambos son sin duda los pilares de la UE. El poder económico alemán superior es evidente pero el peso político y la membrecía nuclear aportan elementos muy importantes en esta relación e influencia en el futuro de la Unión. El predominio alemán desde ya le han merecido críticas de parte de quienes dicen que el proceso está bajo el control de esta potencia.

El peso de la Unión recaerá, una vez más, en los fundadores de este proceso de integración, Alemania y Francia quienes han permanecido comprometidos en la construcción de una unión no solo comercial sino política. El euro, la zona Schengen, la institucionalidad comunitaria son evidencia de los esfuerzos y logros en este sentido. Ante el Brexit, ambos Estados han renovado su apuesta por una Europa unida.

La búsqueda de equilibrio entre las principales potencias de la Unión será el reto mayor para repartir responsabilidades y tareas y para no dejar que percepciones de posiciones abusivas se impongan generando desconfianza entre los demás miembros.

Finalmente, un efecto intangible pero de mucha sensibilidad es que el Brexit siente un mal precedente. El proceso de «divorcio» está en marcha y son muchos los ojos atentos a su impacto y a los resultados de las negociaciones que darán forma a la «nueva» relación.

\section{Europeísmo o euroescepticismo}

Como hemos señalado, el Brexit y el auge de los populismos han vuelto a poner sobre la mesa el debate entre nación o Europa. Muchos han tratado de presentar el voto británico como evidencia del fracaso de la UE en distintos grados, denunciando la gran brecha entre las élites y los ciudadanos, entre Bruselas y los miembros, hasta llegar incluso a cuestionarse en algunos casos el orden económico. El europeísmo 
o eurofobia creyó que podía seguir el impulso del Reino Unido y sumarse a esta tendencia. Sin embargo, esto no ocurrió o no ha ocurrido hasta el momento.

Prueba de este efecto fueron el fracaso de representantes de este movimiento poco después del Brexit en elecciones en Holanda, Austria, Francia. Sin embargo, las tendencias eurofóbicas, lideradas por partidos nacionalistas populistas no han desaparecido y siguen pugnando por prevalecer en varios Estados de la Unión.

Así como las negociaciones para afrontar la crisis del euro llevaron a posiciones conjuntas aunque con un costo alto para la relación entre UE, la incertidumbre frente al resultado del referéndum en el Reino Unido curiosamente podría menguar la fuerza de los movimientos que pretenden seguirle los pasos. La preocupación respecto al futuro pos Brexit para este país puede ser disuasivo dado que si la situación no se ve clara a casi dos años del referéndum. Incluso, al interior de este reino, las voces que piden revisar la decisión o retroceder aumentaron aunque en términos políticos los procedimientos han continuado. Si el «divorcio» es tan difícil para una potencia de las dimensiones del Reino Unido, será peor para quienes no detentan dicha posición al interior de la Unión.

El peligro del efecto contagio no se ha manifestado de inmediato pero pese al elemento disuasivo de la gran incertidume que tińe el Brexit, este está latente en la región y existe una legítima preocupación por su multiplicación. Es claro que el impacto del Brexit no es comparable al que podrían tener la salida de alguno de otros países miembros, donde los movimientos en este sentido se están dando. No se trata de menospreciar la relevancia de Grecia, Italia o Austria en la Unión pero hay que considerar el peso político y económico específico que representa el Reino Unido en el escenario regional e internacional.

De este modo, consideramos que el Brexit podría ser la oportunidad para un proceso introspectivo en la Unión Europea que identifique las fortalezas y debilidades de la integración. Hay frases pos Brexit que se oyen, como que «solo Europa puede vencer al nacionalismo europeo», que resultan no solo efectistas sino que reflejan la permanencia de esta apuesta de larga data.

Un mundo sin la UE es difícil de imaginar. Cumple sin duda un rol de balance a nivel regional e internacional, y su papel como garante de paz y prosperidad no ha cesado. La UE es un actor muy relevante del orden mundial. Creemos que lo que está ocurriendo es un proceso de adaptación en tiempos de reconfiguración fundamentalmente de los órdenes regionales. Reformas, ajustes, deben hacerse, no hay recetas infalibles. La UE no es un proceso perfecto y el Brexit debe llamar la atención a sus arquitectos respecto a sus debilidades y necesidades de eventuales flexibilidades y reformas de forma y de fondo. En particular, se requiere de una mayor participación 
ciudadana en los procesos de decisión para acortar brechas con Bruselas y dotar al proceso de una mayor legitimidad; ajustes en la zona euro; fortalecimiento de la identidad europea; entre otros temas que, sin duda, seguirán discutiéndose en el seno de la Unión.

Los tiempos del Estado nación no han muerto pero tampoco estamos en un mundo de Estados aislados con capacidad de resolver solos todo lo que les afecta. Estamos en un mundo globalizado, interdependiente, en el que las fórmulas nacionales conviven con las intergubernamentales o supranacionales establecidas para dar mejor respuesta a los retos que se enfrentan.

El Brexit es una señal de alerta que la Europa unida tendrá que escuchar con atención a fin de que las recetas antisistema, eurofóbicas no ganen espacio. La Unión Europea ha vivido marchas y contramarchas, se ha ido adaptando a los tiempos superando obstáculos a través de su historia. Hoy le toca continuar con los esfuerzos para atender la agenda comunitaria y ver en esta crisis una oportunidad para atender los temas pendientes, realizar las reformas necesarias y fortalecer este emblemático proceso.

\section{Referencias}

Barbé, E. (1995). Relaciones internacionales. Madrid: Tecnos.

Bejar, M.D. (2011). Historia del siglo XX. Europa, América, Asia, África y Oceanía. Buenos Aires: Biblioteca Básica de Historia, Siglo Veintiuno Editores.

Butros Gali, B. (1992). Un programa de paz. Diplomacia preventiva, establecimiento de la paz y mantenimiento de la paz. Nueva York: Naciones Unidas.

Calduch, R. (1991). Relaciones Internacionales. Madrid: Ediciones Ciencias Sociales.

Hall, P. (28 de junio de 2016). The Roots of Brexit. 1992, 2004, and European Union Expansion. En Foreign Affairs, https://www.foreignaffairs.com/articles/ united-kingdom/2016-06-28/roots-brexit.

Moreno Juste, A. (2001). El proceso de construcción europea: de la CECA al Tratado de Maastricht. En J.C. Pereira (Coord.), Historia de las relaciones internacionales contemporáneas (pp. 561-584). Barcelona: Ariel.

Morillas, P. (2016). 'Brexit': una mala opción para Europa. Estudios de Politica Exterior, Recuperado de https://www.politicaexterior.com/articulos/economia-exterior/ brexit-una-mala-opcion-para-europa/

Oman, C.P. (1996). Los desafios politicos. Globalización y regionalización. Lima: Fundación Friedrich Ebert.

Seoane, J. y Taddei, E. (2001). De Seattle a Porto Alegre. Pasado, presente y futuro del movimiento anti mundialización neoliberal. En J. Seone y E. Taddei. Resistencias mundiales (pp. 105-129). Buenos Aires: Clasco, Buenos Aires. 
Stiglitz, J. (2002). El malestar de la globalización. Buenos Aires: Taurus.

Stiglitz, J. (2012). El precio de la desigualdad. Madrid: Editorial Taurus.

Stiglitz, J. (2016). El euro. Cómo la moneda común amenaza el futuro de Europa. Barcelona: Taurus.

Unión Europea (2018). Qué es la UE. Recuperado de https://europa.eu/european-union/ about-eu/eu-in-brief_es

Fecha de recepción: 18 de marzo de 2018

Fecha de aprobación: 23 de junio de 2018 